\title{
Staphylococcus aureus $\alpha$-Toxin Induces Inflammatory Cytokines via Lysosomal Acid Sphingomyelinase and Ceramides
}

\author{
Jie Ma ${ }^{a}$ Erich Gulbins ${ }^{a, b}$ Michael J. Edwards ${ }^{b}$ Charles C. Caldwell ${ }^{b}$ \\ Martin Fraunholz ${ }^{c}$ Katrin Anne Becker ${ }^{a}$ \\ aDept. of Molecular Biology, Medical School, University of Duisburg-Essen, Essen, Germany; \\ 'Dept. of Surgery, University of Cincinnati, College of Medicine, University of Cincinnati, Cincinnati, \\ USA; 'Chair of Microbiology, University of Würzburg, Würzburg, Germany
}

\section{Key Words}

Staphylococcus aureus $\cdot$ Sphingomyelinase $\cdot$ Ceramide, toxins $•$ Macrophages $・$ Cytokines

\begin{abstract}
Background/Aims: Staphylococcus aureus (S. aureus) infections are a major clinical problem and range from mild skin and soft-tissue infections to severe and even lethal infections such as pneumonia, endocarditis, sepsis, osteomyelitis, and toxic shock syndrome. Toxins that are released from $S$. aureus mediate many of these effects. Here, we aimed to identify molecular mechanisms how $\alpha$-toxin, a major S. aureus toxin, induces inflammation. Methods: Macrophages were isolated from the bone marrow of wildtype and acid sphingomyelinasedeficient mice, stimulated with $S$. aureus $\alpha$-toxin and activation of the acid sphingomyelinase was quantified. The subcellular formation of ceramides was determined by confocal microscopy. Release of cathepsins from lysosomes, activation of inflammasome proteins and formation of Interleukin-1 $\beta$ (IL-1 $\beta$ ) and Tumor Necrosis Factor- $\alpha$ (TNF- $\alpha$ ) were analyzed by western blotting, confocal microscopy and ELISA. Results: We demonstrate that $S$. aureus $\alpha$-toxin activates the acid sphingomyelinase in ex vivo macrophages and triggers a release of ceramides. Ceramides induced by $S$. aureus $\alpha$-toxin localize to lysosomes and mediate a release of cathepsin B and D from lysosomes into the cytoplasm. Cytosolic cathepsin B forms a complex with NIrc4. Treatment of macrophages with $\alpha$-toxin induces the formation of IL-1 $\beta$ and TNF- $\alpha$. These events are reduced or abrogated, respectively, in cells lacking the acid sphingomyelinase and upon treatment of macrophages with amitriptyline, a functional inhibitor of acid sphingomyelinase. Pharmacological inhibition of cathepsin B prevented activation of the inflammasome measured as release of IL-1 $\beta$, while the formation of TNF- $\alpha$ was independent of cathepsin B. Conclusion: We demonstrate a novel mechanism how bacterial toxins activate the inflammasome and mediate the formation and release of cytokines: $S$. aureus $\alpha$-toxin triggers an activation of the acid sphingomyelinase and a release of ceramides resulting in the release of lysosomal cathepsin B and formation of pro-inflammatory cytokines.




\section{Cellular Physiology Cell Physiol Biochem 2017;43:2170-2184

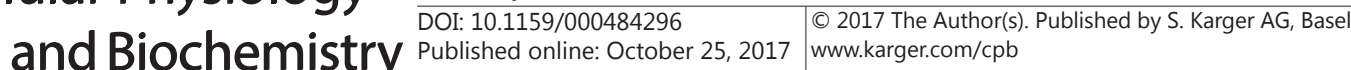 \\ Ma et al.: Staphylococcus aureus $\alpha$-Toxin Activates the Inflammasome}

\section{Introduction}

Staphylococcus aureus (S. aureus) often infects the skin and soft tissues resulting in local symptoms, e.g. purulent wound infections, but $S$. aureus can also cause severe infections such as pneumonia, endocarditis, osteomyelitis, sepsis, and toxic shock syndrome [1]. Most importantly, many $S$. aureus strains have developed resistance to available antibiotics, and in particular methicillin-resistant $S$. aureus (MRSA) strains constitute a major clinical problem [2].

$S$. aureus release a variety of toxins that mediate many effects of this pathogen. These toxins include enterotoxins, $\alpha$-toxin, hemolysin $\gamma$, and Panton-Valentine leukocidin, leukocidins, and $\gamma$-toxin [3-7]. These toxins trigger membrane permeabilization and damage by pore formation, induce inflammation characterized by increased vascular permeability, infiltration of neutrophils and macrophages and cytokine production or mediate cell death resulting in typical pus formation [3-7]. Toxins are also critically involved in the pathogenesis of systemic symptoms of $S$. aureus infections such as pneumonia and sepsis [5, 7].

In vivo experiments using $S$. aureus mutants lacking the pore-forming $\alpha$-toxin revealed that this toxin is one of the most important virulence factors of $S$. aureus and its deletion greatly reduces mortality of $S$. aureus pneumonia [7-9]. S. aureus $\alpha$-toxin binds to A-disintegrin And Metalloprotease 10 (ADAM10) [10,11]. ADAM10 is not only the eukaryotic receptor for $\alpha$-toxin, but also mediates the proper assembly of the toxin, which is a pre-requisite of the integration of $\alpha$-toxin into cell membranes [10]. Binding of $\alpha$-toxin to ADAM10 is necessary for $\alpha$-toxin-induced cytotoxicity and the disruption of epithelial and endothelial barriers [811]. However, the molecular details of this process are unknown, in particular since a recent study demonstrated that the enzyme activity of ADAM10 is not required for at least some of the effects of $\alpha$-toxin [12].

We have previously shown that several pathogens, e.g. Neisseria gonorrhoeae, Pseudomonas aeruginosa ( $P$. aeruginosa), $S$. aureus or rhinovirus activate the acid sphingomyelinase and mediate a release of ceramides in epithelial and endothelial cells, macrophages and neutrophils [13-22]. The acid sphingomyelinase is a lysosomal enzyme that is present in lysosomes and secretory lysosomes [23-25]. The fusion of secretory lysosomes with the plasma membrane results in surface exposure of the acid sphingomyelinase and a release of ceramides on the outer leaflet of the plasma membrane [25]. Ceramide molecules spontaneously aggregate and form small domains that fuse to larger ceramide-enriched membrane platforms that serve to re-organize and cluster receptors and signaling molecules $[25,26]$. The generation of ceramide molecules within membranes also changes membrane properties and membrane fluidity [27-31]. The re-organization of receptors and associated signaling molecules mediates many of the cellular effects of ceramides [25]. In contrast to the well-characterized function of surface acid sphingomyelinase and ceramides, the role of intracellular/intralysosomal acid sphingomyelinase and ceramide is poorly characterized. Thus, it was shown that lysosomal ceramides bind to cathepsin $\mathrm{D}$ and mediate a release of cathepsin D from lysosomes [32, 33]. In addition, the acid sphingomyelinase and ceramides have been implied in the regulation of inflammation and in activation of the inflammasome $[34,35]$, a multiprotein complex that culminates in stimulation of caspases, in particular caspase 1 , and the release of Interleukin-1 $\beta$ (IL-1 $\beta$ ) and other cytokines [36].

Here, we tested whether $\alpha$-toxin activates the acid sphingomyelinase/ceramide system in macrophages and whether it triggers lysosomal ceramides to activate the inflammasome. We demonstrate that $S$. aureus $\alpha$-toxin activates the acid sphingomyelinase in ex vivo bone marrow-derived macrophages and triggers a release of ceramides mainly in lysosomes. The release of ceramides in lysosomes upon $\alpha$-toxin treatment results in an increase of lysosomal permeability and a translocation of cathepsin B and D from lysosomes into the cytoplasm. Cathepsin B associates with the inflammasome protein Nlrc4, activates the inflammasome and mediates the release of IL-1 $\beta$, which is inhibited by pharmacological blockade of cathepsin $B$. In contrast, $\alpha$-toxin also induces a massive release of TNF- $\alpha$ from macrophages, which is not affected by cathepsin B inhibition. All of these events are prevented in macrophages 


\section{Cellular Physiology Cell Physiol Biochem 2017;43:2170-2184

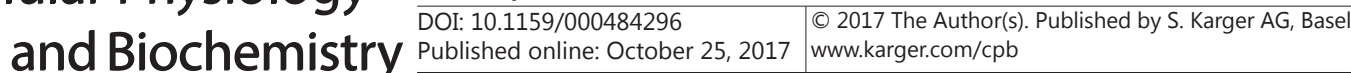

Ma et al.: Staphylococcus aureus $\alpha$-Toxin Activates the Inflammasome

genetically deficient for the acid sphingomyelinase or treated with the functional inhibitor of the acid sphingomyelinase amitriptyline.

\section{Materials and Methods}

\section{Mice and Ethics Statement}

Acid sphingomyelinase (Asm)-deficient mice [37] (sphingomyelin phosphodiesterase 1 knockout; Smpd1 $1^{--}$) and wildtype littermates (WT) mice were maintained on a C57BL/6 background. The genotype was determined by polymerase chain reaction. Mice were used at an age between 6 to 8 weeks to avoid sphingomyelin accumulation [38]. Mice were bred in the animal facility of the University of Duisburg-Essen under specific pathogen-free (SPF) conditions, according to the criteria of the Federation of Laboratory Animal Science (FELASA). All experiments were done according to the rules of the FELASA.

\section{Bone marrow-derived macrophages}

Bone marrow-derived macrophages (BMDMs) were prepared and cultured as previously described [39]. Mice were sacrificed, femurs and tibias were prepared and the bone marrow was flushed out with minimum essential medium (MEM; Invitrogen) supplemented with 10\% fetal bovine serum, 10 mM HEPES (Roth GmbH; pH 7.4), $2 \mathrm{mM}$ L-glutamine, $1 \mathrm{mM}$ sodium pyruvate, $100 \mu \mathrm{M}$ non-essential amino acids, $100 \mathrm{U} /$ $\mathrm{mL}$ penicillin, and $100 \mu \mathrm{g} / \mathrm{mL}$ streptomycin (all from Invitrogen). Cells were isolated by repeated pipetting and cultured for $24 \mathrm{hrs}$. Non-adherent cells were carefully removed, washed, counted and cells were cultured in 6- or 24-well plates in MEM with 20\% L-cell supernatant, which contains macrophage colony-stimulating factor required for macrophage growth and differentiation. We used $1 \times 10^{5}$ cells for all microscopy studies, $1 \times 10^{6}$ cells for measurement of the acid sphingomyelinase and ceramides and western blot studies and $2 \times 10^{6}$ cells for immunoprecipitations, respectively. If the cells were used for immunofluorescence and confocal microscopy studies, we cultured them on small glass slides fitting into the wells of a 24-well plate. For all other experiments, macrophages were directly cultured in the 6-well plate. Fresh MEM/L-cell supernatant media was applied after 4 days of culture. Macrophages mature within the next 6 days and were used on day 10 of culture.

Stimulation of bone marrow cells with S. aureus $\alpha$-toxin

S. aureus $\alpha$-toxin was obtained from Sigma, dissolved in sterile PBS and used at a final concentration of $10 \mu \mathrm{g} / \mathrm{mL}$ to stimulate the cells for the indicated times.

Cells were pre-treated with amitriptyline $(25 \mu \mathrm{M}$, Sigma) for $60 \mathrm{~min}$ in MEM supplemented with 10 mM HEPES (pH 7.4) or with the cathepsin B inhibitor CA-074Me (50 $\mu$ M, Sigma) for $30 \mathrm{~min}$.

\section{Acid sphingomyelinase activity}

Cells were treated with S. aureus $\alpha$-toxin or left untreated, lysed in $200 \mu \mathrm{L}$ of $250 \mathrm{mM}$ sodium acetate (pH 5.0 ) and 1\% NP40 for 10 min and shock-frozen in liquid nitrogen. The protein concentration was measured in an aliquot by a Bradford protein assay (BioRad). The samples were thawed and aliquots corresponding to $2 \mu \mathrm{g}$ of protein were diluted into $250 \mathrm{mM}$ sodium acetate ( $\mathrm{pH}$ 5.0) and $0.1 \% \mathrm{NP} 40$. The enzyme reaction was started by addition of 100 pmol BODIPY-FL $\mathrm{C}_{12}$-sphingomyelin (Thermo Fisher) and the samples were incubated at $37^{\circ} \mathrm{C}$ for $1 \mathrm{~h}$ with shaking at $300 \mathrm{rpm}$. The reaction was stopped by the addition of $250 \mu \mathrm{L}$ chloroform:methanol $(2: 1, \mathrm{v} / \mathrm{v})$, samples were centrifuged for $5 \mathrm{~min}$ at 22,000 $\times \mathrm{g}(14,000 \mathrm{rpm})$, an aliquot of the lower phase was dried in a SpeedVac Concentrator (Thermo Fisher Scientific) and resuspended in $10 \mu \mathrm{L}$ of chloroform:methanol $(2: 1, \mathrm{v} / \mathrm{v})$. The samples were spotted onto a thin-layer chromatography (TLC) plate (Merck) and separated with chloroform:methanol (80:20, v/v). TLC plates were analyzed using a Typhoon FLA 9500 laser scanner (GE Healthcare Life Sciences, USA) and ImageQuant software (GE Healthcare Life Sciences).

\section{Immunostainings}

Macrophages were cultured on coverslips, washed and stimulated with $S$. aureus $\alpha$-toxin as above or left untreated in MEM supplemented with $10 \mathrm{mM}$ HEPES, pH 7.4. The medium was removed and cells were immediately fixed in $4 \%$ paraformaldehyde (PFA; Sigma) in PBS (pH 7.4) for 10 min. Cells were then washed 3 times with PBS and permeabilized with $0.1 \%$ Triton X-100 in PBS for $10 \mathrm{~min}$ at room temperature. Cells were washed again with PBS and blocked for 15 min with 5\% FCS in HEPES/Saline (H/S) buffer consisting 


\section{Cellular Physiology Cell Physiol Biochem 2017;43:2170-2184 \begin{tabular}{l|l|l} 
and Biochemistry 10.1159/000484296 & $\begin{array}{l}\text { C) } 2017 \text { The Author(s). Published by S. Karger AG, Basel } \\
\text { www.karger.com/cpb }\end{array}$
\end{tabular} \\ Ma et al.: Staphylococcus aureus $\alpha$-Toxin Activates the Inflammasome}

of $132 \mathrm{mM} \mathrm{NaCl}, 20 \mathrm{mM}$ HEPES (pH 7.4), $5 \mathrm{mM} \mathrm{KCl}, 1 \mathrm{mM} \mathrm{CaCl}{ }_{2}, 0.7 \mathrm{mM} \mathrm{MgCl}_{2}$, and $0.8 \mathrm{mM} \mathrm{MgSO}$ to block non-specific binding. Cells were washed again and then incubated for $60 \mathrm{~min}$ with anti-ceramide antibodies (diluted 1:100, mouse monoclonal IgM; Glycobiotech), anti-Lamp-1 (1:200, Abcam \#24245), anti-cathepsin D (1:100, R\&D \#AF1024), anti-cathepsin B (1:100, R\&D \#AF965), anti-Nlrc4 (1:50, Lifespan Biosciences \#Ls-c148271-50) or anti-Asc (1:100, Santa Cruz Inc. \#sc30153), respectively. All antibodies were diluted in PBS, 5\% FCS. Samples that were co-stained with two antibodies were incubated consecutively with the antibodies and the samples were washed 3 times with 0.05\% Tween-20/PBS for 5 min between the incubations. After the last incubation, cells were washed again 3 times for 5 min each and incubated with FITC- or Cy3-conjugated $\mathrm{F}\left(\mathrm{ab}^{\prime}\right)_{2}$ fragments of secondary antibodies corresponding to the primary antibodies. All antibodies were from Jackson ImmunoResearch.

Finally, the samples were washed again 3 times with $0.05 \%$ Tween 20/PBS and once in PBS and were mounted with Mowiol (Kuraray Specialities Europe GmbH). Samples were analyzed with a Leica TCS SP5 confocal microscope and Leica LCS software (Leica Microsystems).

Western blot and immunoprecipitation studies

Whole cell lysates: Cells $\left(1 \times 10^{6}\right)$ were lysed in ice-cold $0.1 \%$ sodium-dodecylsulfate (SDS), $25 \mathrm{mM}$ HEPES, $0.5 \%$ deoxycholate, $0.1 \%$ Triton X-100, $10 \mathrm{mM}$ ethylenediaminetetraacetic acid (EDTA), $10 \mathrm{mM}$ sodium pyrophosphate, $10 \mathrm{mM}$ sodium fluoride, $125 \mathrm{mM} \mathrm{NaCl}$, and $10 \mu \mathrm{g} / \mathrm{mL}$ aprotinin/leupeptin (all from Sigma). Lysis was allowed to complete for $5 \mathrm{~min}$ on ice. Samples were then centrifuged at 22,000 $\times \mathrm{g}$ for 5 $\mathrm{min}$ at $4^{\circ} \mathrm{C}$ to pellet insoluble material, the supernatants were collected and added to $5 \mathrm{x}$ SDS Laemmli sample buffer. Samples were incubated at $95^{\circ} \mathrm{C}$ for $5 \mathrm{~min}$ and proteins were separated by $10 \%$ SDS polyacrylamide gel electrophoresis (SDS-PAGE). Proteins were electrophoretically transferred to nitrocellulose membranes and blocked with $5 \%$ bovine serum albumin (BSA) in Tris-buffered saline supplemented with $0.05 \%$ Tween 20. Blots were incubated overnight at $4^{\circ} \mathrm{C}$ with anti-cathepsin D (diluted 1:1000, R\&D \#AF1024) or anti-cathepsin B (1:1000, R\&D \#AF965), respectively. Blots were washed and developed with alkaline phosphatase-coupled secondary antibodies (1:20 000; Santa Cruz Biotechnology Inc.) using the Tropix chemoluminescence system (Amersham Pharmacia Biotech Inc.).

Separation of cytoplasmic from lysosomal proteins: Cells $\left(1 \times 10^{6}\right)$ were lysed in ice-cold $50 \mu \mathrm{g} / \mathrm{mL}$ Digitonin, $150 \mathrm{mM} \mathrm{NaCl}, 50 \mathrm{mM}$ HEPES (pH 7.4), $10 \mathrm{~g} / \mathrm{mL}$ aprotinin/leupeptin (all from Sigma), incubated on ice for $10 \mathrm{~min}$ and centrifuged at 2,000 $\times \mathrm{g}$ for $5 \mathrm{~min}$ at $4^{\circ} \mathrm{C}$ to pellet insoluble material. The supernatants were collected, processed as above and blotted with anti-cathepsin B or anti-cathepsin D antibodies.

Co-immunoprecipitations: Cells $\left(2 \times 10^{6}\right)$ were stimulated with $S$. aureus $\alpha$-toxin or left untreated, lysed in $0.1 \%$ SDS, 25 mM HEPES, $0.5 \%$ deoxycholate, $0.1 \%$ Triton X-100, $10 \mathrm{mM}$ EDTA, $10 \mathrm{mM}$ sodium pyrophosphate, $10 \mathrm{mM}$ sodium fluoride, $125 \mathrm{mM} \mathrm{NaCl}$, and $10 \mu \mathrm{g} / \mathrm{mL}$ aprotinin/leupeptin (all from Sigma) for $5 \mathrm{~min}$ and centrifuged at $22,000 \times \mathrm{g}, 4^{\circ} \mathrm{C}$ for $5 \mathrm{~min}$. Samples were incubated on a nutator for $4 \mathrm{hrs}$ with anti-Nlrc4 antibodies (1 $\mu \mathrm{g} / \mathrm{mL}$, LifeSpan BioSciences \#Ls-c148271-50) or anti-NLRP3 (1 $\mu \mathrm{g} / \mathrm{mL}$, Adipogen life sciences \#AG-20B-0014-C100) followed by incubation with $30 \mu \mathrm{L}$ protein A/G agarose (Santa Cruz Inc.) for $45 \mathrm{~min}$. The immune-complexes were washed 6 times in lysis buffer as above and proteins were eluted in 1x SDS Laemmli sample buffer. Samples were processed as above and blotted for cathepsin B or cathepsin D.

ELISA

ELISA assays for IL-1 $\beta$ and TNF- $\alpha$ were performed as described by the vendor (R\&D). We used cell pellets and the culture supernatants for ELISA assays.

\section{Statistics}

Data are given as arithmetic means \pm standard deviation (SD). One-way analysis of variance (ANOVA) with Bonferroni correction followed by the Student-Newman-Keuls test was used to test for multiple comparisons. Statistical significance was set at the level of $p<0.05$. All data were obtained from independent measurements.

\section{Results}

S. aureus $\alpha$-toxin activates the acid sphingomyelinase

In order to test whether $S$. aureus $\alpha$-toxin activates the acid sphingomyelinase/ ceramide system to induce inflammation, we tested whether treatment of bone marrow- 


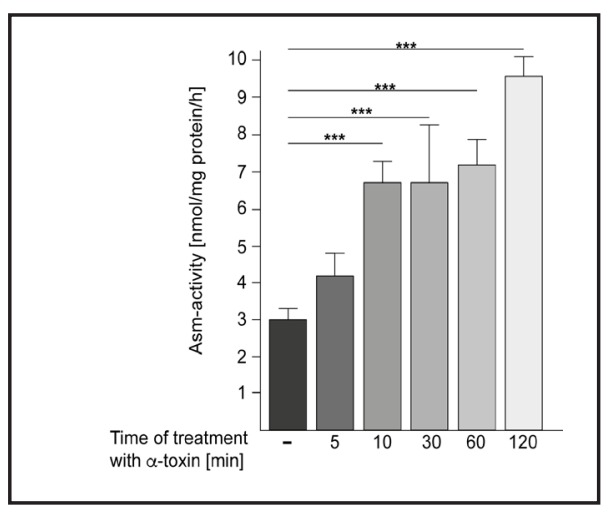

Fig. 1. $S$. aureus $\alpha$-toxin induces an activation of the acid sphingomyelinase. Bone marrow-derived macrophages were activated with $5 \mu \mathrm{g} / \mathrm{mL}$ S. aureus $\alpha$-toxin for the indicated time, lysed and the activity of the acid sphingomyelinase was determined in the cell extracts by consumption of BODIPYlabeled sphingomyelin. Shown is the mean \pm SD of 4 independent studies, $p<0.05$, ANOVA.

derived macrophages with $\alpha$-toxin results in an activation of the acid sphingomyelinase. Biochemical studies demonstrate a sustained activation of the acid sphingomyelinase upon treatment of wildtype (WT) macrophages with $\alpha$-toxin (Fig. 1).

S. aureus $\alpha$-toxin induces lysosomal ceramides and a release of cathepsin B and D from lysosomes via the acid sphingomyelinase

Confocal microscopy studies on macrophages stained with Cy3anti-ceramide and FITC-anti-Lamp-1 antibodies (the latter one served to detect lysosomes) revealed that most of the ceramides triggered by treatment of WT macrophages with $\alpha$-toxin localized to lysosomes (Fig. 2A). The increase of lysosomal ceramides upon treatment with $\alpha$-toxin was absent in macrophages lacking the acid sphingomyelinase (Fig. 2A).

To confirm the notion of lysosomal release of ceramides upon treatment of macrophages with $\alpha$-toxin, we co-stained macrophages with anti-ceramide, anticathepsin B and anti-cathepsin D antibodies. Cathepsin B and D also localize to lysosomes. The studies confirm a release of ceramides in lysosomes of WT macrophages, which was absent in lysosomes of cells lacking the acid sphingomyelinase (Fig. 2B and C). However,

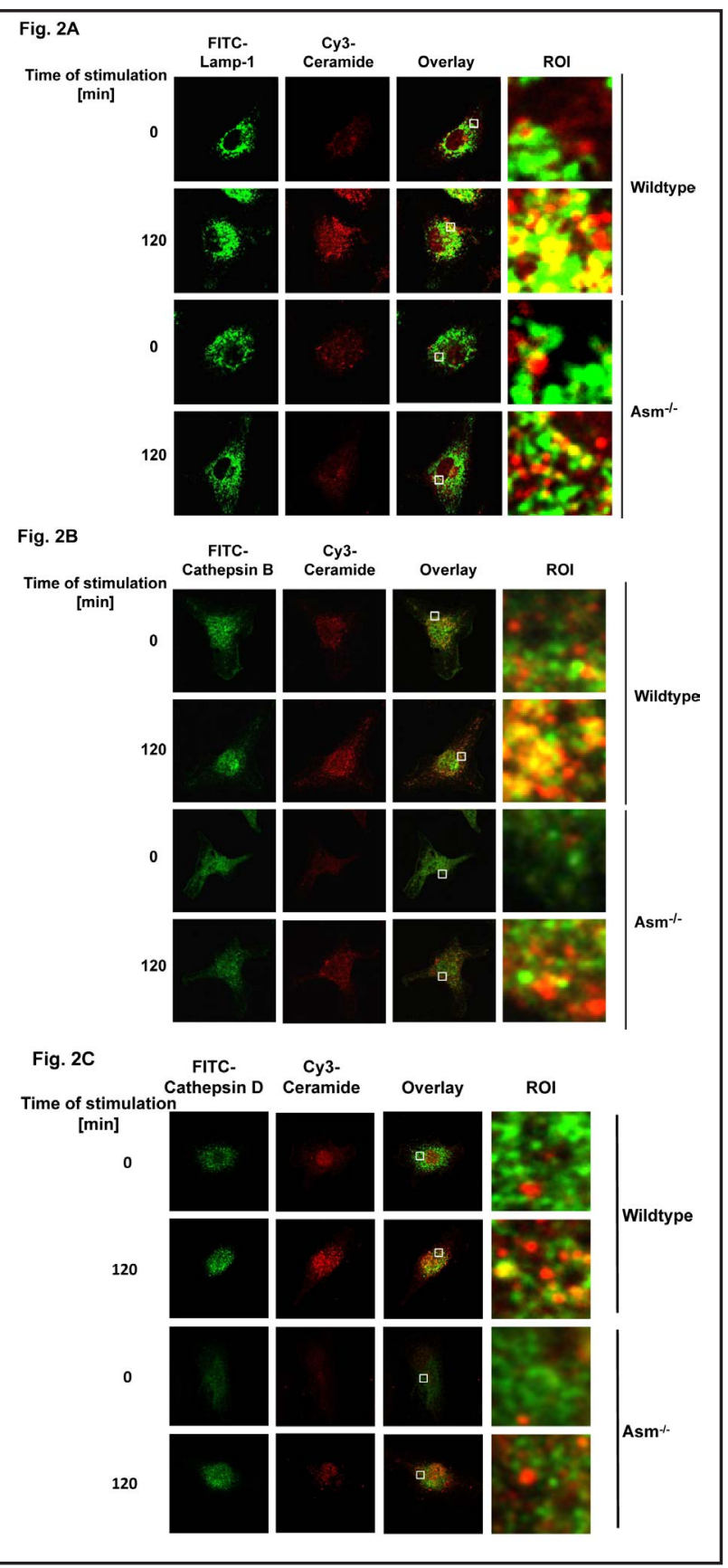

Fig. 2. S. aureus $\alpha$-toxin induces formation of ceramides within lysosomes. Confocal microscopy studies staining for ceramide and Lamp-1 (A), cathepsin B (B) and cathepsin D (C) as lysosomal markers reveal a lysosomal release of ceramides after stimulation with $S$. aureus $\alpha$-toxin, which is absent in cells lacking the acid sphingomyelinase (Asm ${ }^{-/}$). Shown are typical confocal microscopy results from each 4 independent studies. 


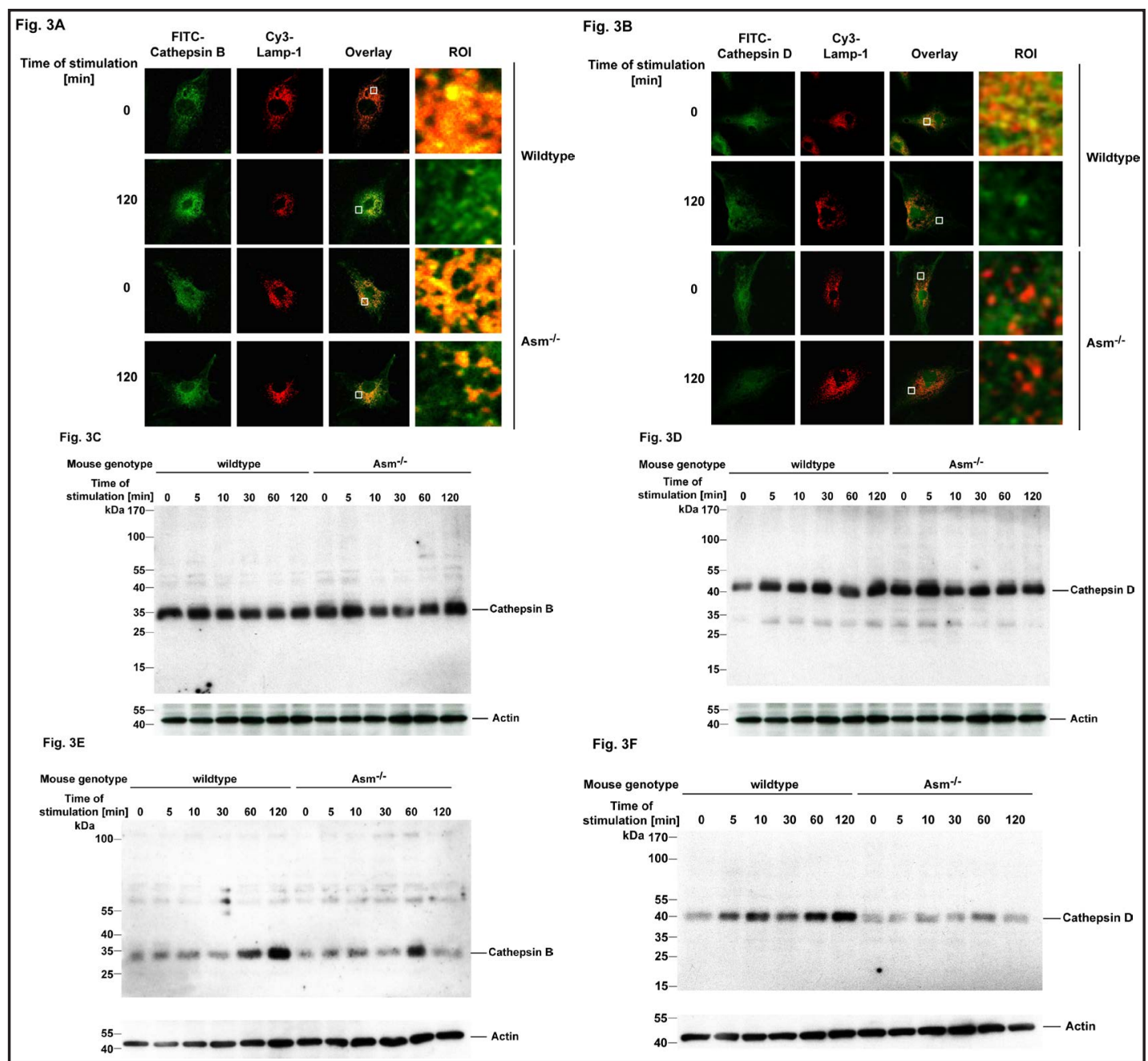

Fig. 3. S. aureus $\alpha$-toxin triggers a release of cathepsin B and D from lysosomes into the cytoplasm, which is prevented by acid sphingomyelinase deficiency. (A, B) Confocal microscopy of $\alpha$-toxintreated or -untreated wildtype and Asm deficient (Asm ${ }^{--}$) macrophages that were stained with anti-cathepsin B or anti-cathepsin D in combination with anti-Lamp-1 antibodies reveals a partial release of cathepsin B and D into the cytoplasm from lysosomes after treatment. The release is prevented by acid sphingomyelinase-deficiency. (C-F) Western blot studies demonstrate a similar expression of cathepsin B (C) and cathepsin D (D) in wildtype and acid sphingomyelinase-deficient $\left(\mathrm{Asm}^{-/}\right)$macrophages. Separation of the cytoplasmic from lysosomal cell fractions reveals that treatment with $S$. aureus $\alpha$-toxin induces a release of cathepsin B (E) and cathepsin D (F) into the cytoplasm of wildtype macrophages. Deficiency of the acid sphingomyelinase prevents the lysosomal release of cathepsins after $\alpha$-toxin treatment (E, F). Actin blots served to demonstrate equal loading in all lanes. Please note that panel $\mathrm{C}$ and $\mathrm{D}$ were from the same lysates and therefore, the actin blots are the same. Shown are representative confocal microscopy studies or blots, respectively, from each 4 (A, B) or 3 (C-F) independent studies.

careful inspection of the confocal microscopy results revealed that a fraction of cathepsin $\mathrm{B}$ and $\mathrm{D}$ did not localize with ceramides after stimulation, leading us to investigate whether $\alpha$-toxin induces a release of cathepsins from lysosomes.

To this end, we co-stained macrophages prior and after stimulation with $\alpha$-toxin for cathepsin B and D and Lamp-1, as marker for lysosomes. While, cathepsin B and D co-localized with Lamp-1 in WT and acid sphingomyelinase-deficient macrophages prior to stimulation with $\alpha$-toxin (Fig. 3A and B), stimulation of the cells with $\alpha$-toxin resulted in a partial dissociation of the signal for cathepsin B and D and Lamp-1 in WT macrophages. This 
indicates a release of cathepsin $\mathrm{B}$ and $\mathrm{D}$ from lysosomes upon stimulation with $\alpha$-toxin. In contrast, in acid sphingomyelinasedeficient macrophages most of the cathepsin $B$ and D remained co-localized with Lamp-1 indicating that $\alpha$-toxin had almost no effect on the localization of the two proteins in acid sphingomyelinase-deficient cells (Fig. 3A and B). However, a small amount of cathepsins was also released in acid sphingomyelinasedeficient cells. To confirm this notion and to quantify the release of cathepsin B and D from lysosomes upon treatment with $\alpha$-toxin, we separated lysosomes from the cytoplasm and performed western blot studies for cathepsin $\mathrm{B}$ and D. Controls, analyzing total cell lysates, show a similar total expression of cathepsin $\mathrm{B}$ and D in WT and acid sphingomyelinasedeficient macrophages (Fig. 3C and D). Western blot studies with cells that were lysed with digitonin to separate cytoplasmic from lysosomal proteins revealed that $\alpha$-toxin induced a marked release of cathepsin B and D from lysosomes in WT cells, while much less cathepsin B and D were released from lysosomes in acid sphingomyelinasedeficient cells upon treatment with $\alpha$-toxin (Fig. 3E and F).

Amitriptyline has been shown to

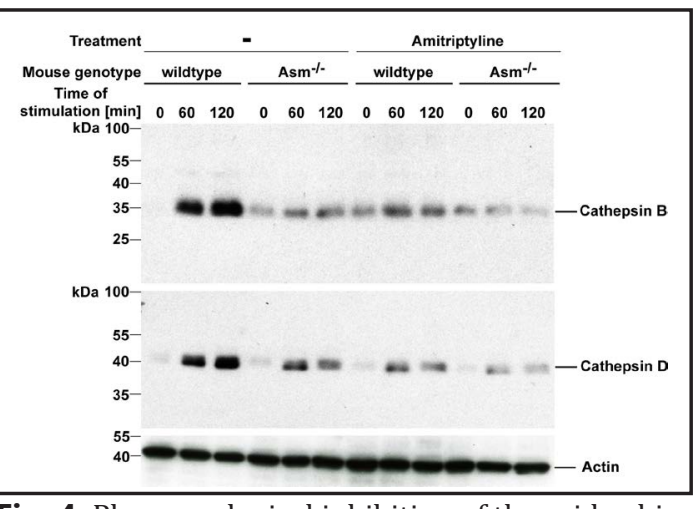

Fig. 4. Pharmacological inhibition of the acid sphingomyelinase prevents the release of cathepsin B and D from lysosomes into the cytoplasm after $S$. aureus $\alpha$-toxin treatment. Cells were pre-treated with amitriptyline, a functional inhibitor of the acid sphingomyelinase, and the release of cathepsin $B$ (upper blot) and cathepsin D (lower blot) from lysosomes into the cytoplasm after treatment with $S$. aureus $\alpha$-toxin was determined by western blotting of cell fractions. Amitriptyline prevented the $S$. aureus $\alpha$-toxin-induced release of cathepsins into the cytoplasm and even further reduced the residual release of cathepsins into the cytoplasm in cells lacking the acid sphingomyelinase $\left(\right.$ Asm $\left.^{-/}\right)$. Actin blots served to demonstrate equal loading in all lanes. Displayed are representative results from each 3 independent studies.

mediate a functional inhibition of the acid sphingomyelinase [40-43]. We therefore tested whether treatment of WT macrophages with amitriptyline blocks the release of cathepsin B and D. The results were consistent with the data obtained in acid sphingomyelinase-deficient cells and showed that amitriptyline inhibits the release of cathepsin B and D from lysosomes into the cytoplasm after treatment with $\alpha$-toxin (Fig. 4). The residual release of cathepsin B and D into the cytoplasm in acid sphingomyelinase-deficient cells after treatment with $\alpha$-toxin was further reduced by pretreatment with amitriptyline.

S. aureus $\alpha$-toxin induces cytokines via the acid sphingomyelinase and lysosomal ceramides

Next, we tested whether activation of the acid sphingomyelinase/ceramide system in lysosomes is linked to activation of the inflammasome and whether such a potential link is mediated by cathepsin B and/or D. To this end, we tested whether cathepsin B and D colocalize with Asc, a central regulator of the inflammasome, after treatment of macrophages with $\alpha$-toxin. Confocal microscopy studies indicated a co-localization of cathepsin B with Asc (Fig. 5A) after treatment of WT macrophages with $\alpha$-toxin, while much less cathepsin B co-localized with Asc in acid sphingomyelinase-deficient cells. In contrast, confocal microscopy revealed that most of the cathepsin D did not co-localize with Asc (Fig. 5B). However, confocal microscopy studies certainly do not allow to determine whether two proteins really associate. We therefore performed co-immunoprecipitation experiments to test whether $\alpha$-toxin induces a true association of Nlrc4, a downstream target of Asc and known to form a complex with Asc in the active inflammasome multiprotein complex, with cathepsin B. These studies demonstrate that Nlrc4 co-precipitated with cathepsin B after treatment of wildtype macrophages with $\alpha$-toxin, while almost no association of Nlrc4 with cathepsin B was detected in acid sphingomyelinase-deficient macrophages treated with 


\section{Cellular Physiology Cell Physiol Biochem 2017;43:2170-2184

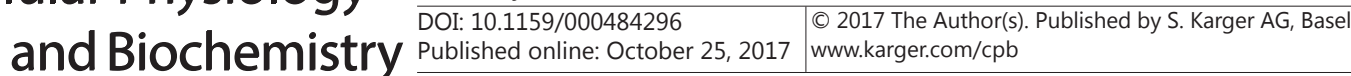

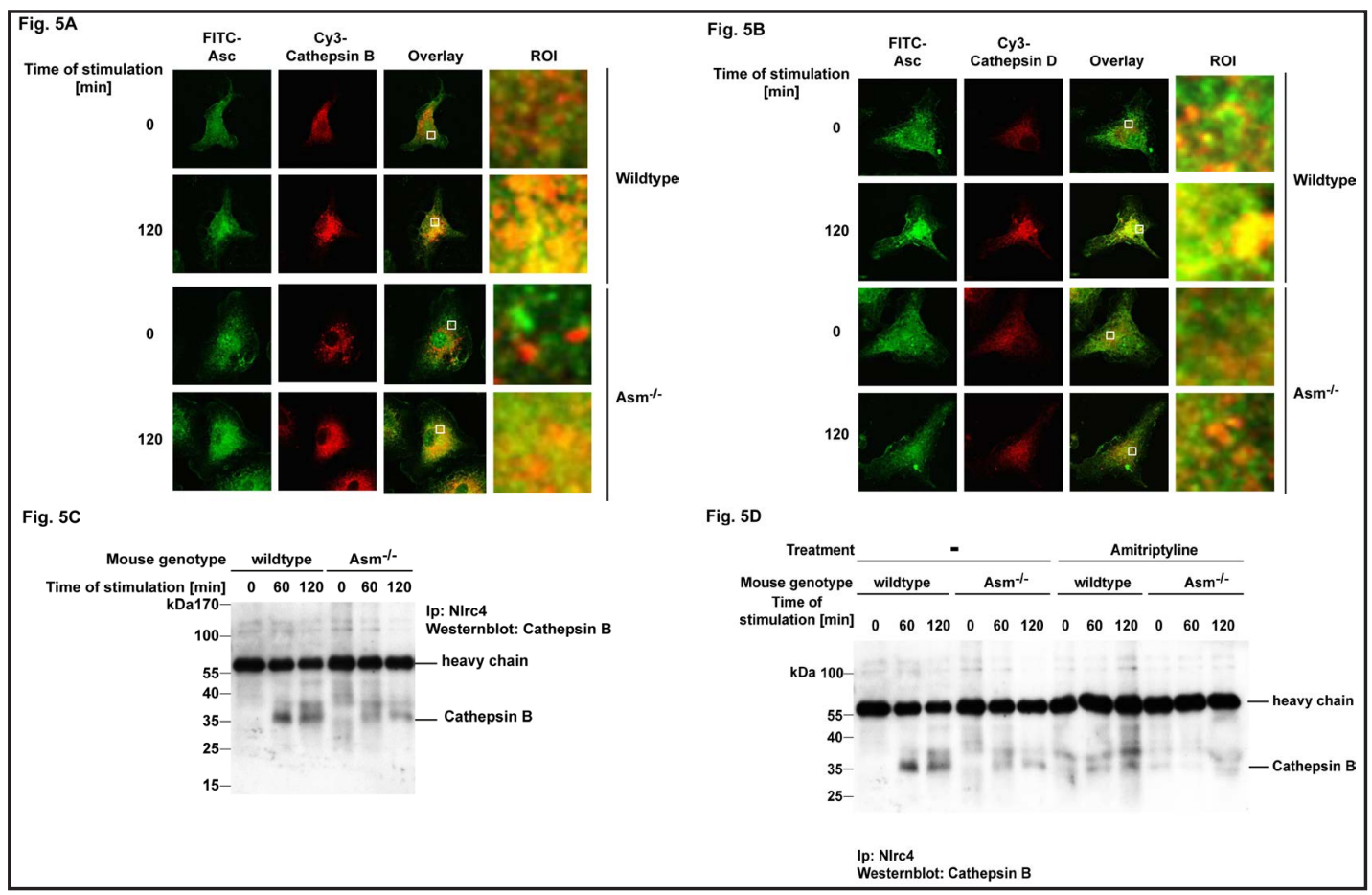

Fig. 5. Cytoplasmic cathepsin B associates with inflammasome proteins. Confocal microscopy (A, B) and co-immunoprecipitation studies (C, D) reveal an association of cathepsin B, but not cathepsin D, with the inflammasome proteins Asc (A, B) and Nlrc4 (C, D) after treatment of macrophages with S. aureus $\alpha$-toxin, which is reduced by genetic deficiency or pharmacological inhibition of the acid sphingomyelinase. In the co-immunoprecipitation experiments we immunoprecipitated Nlrc4 and blotted for cathepsin B (C, D). Shown are representative results from each 4 (A, B) or 3 (C, D) independent studies.

$\alpha$-toxin (Fig. 5C). Likewise, pretreatment with amitriptyline reduced the association of Nlrc4 with cathepsin B after stimulation of wildtype macrophages with $\alpha$-toxin (Fig. 5D). We did not detect a significant effect of $\alpha$-toxin on the association of Nlrc4 with cathepsin D in coimmunoprecipitation experiments (not shown).

To determine the significance of the ceramide-mediated release of cathepsin B from lysosomes and its association with Nlrc 4 , we determined the formation of IL-1 $\beta$ and TNF- $\alpha$ in WT, acid sphingomyelinase-deficient and amitriptyline-treated WT macrophages after treatment with $\alpha$-toxin (Fig. 6A and B). In addition, we measured the release of IL-1 $\beta$ and TNF- $\alpha$ in the cell culture supernatants (Fig. 6C and D). These studies revealed a marked, time-dependent formation of IL- $1 \beta$ and TNF- $\alpha$ in WT macrophages after stimulation with $\alpha$-toxin, which was reduced in acid sphingomyelinase-deficient macrophages or WT macrophages treated with amitriptyline (Fig. 6A and B). Amitriptyline had no effect on the residual formation of IL-1 $\beta$ and TNF- $\alpha$ in acid sphingomyelinase-deficient macrophages after $\alpha$-toxin stimulation (Fig. 6A and B), indicating that the inhibitory effect of amitriptyline on the release of these cytokines is entirely mediated by the acid sphingomyelinase. Treatment with the cathepsin B inhibitor further reduced IL-1 $\beta$ formation in acid sphingomyelinasedeficient cells (Fig. 6A) suggesting that a small part of cathepsin B is released from lysosomes independent of acid sphingomyelinase expression.

IL-1 $\beta$ and TNF- $\alpha$ were released from WT macrophages after stimulation with $\alpha$-toxin (Fig. 6C and D). Treatment with amitriptyline or genetic deficiency prevented the release of IL-1 $\beta$ completely and reduced the release of TNF- $\alpha$ (Fig. $6 \mathrm{C}$ and D).

To test the role of cathepsin B for the release of IL-1 $\beta$ after $\alpha$-toxin stimulation, we treated WT and acid sphingomyelinase-deficient macrophages with the cathepsin B inhibitor CA-074Me $(50 \mu \mathrm{M})$. These studies revealed that the cathepsin B inhibitor reduced the formation and the release of IL- $1 \beta$ from WT macrophages after $\alpha$-toxin stimulation and 


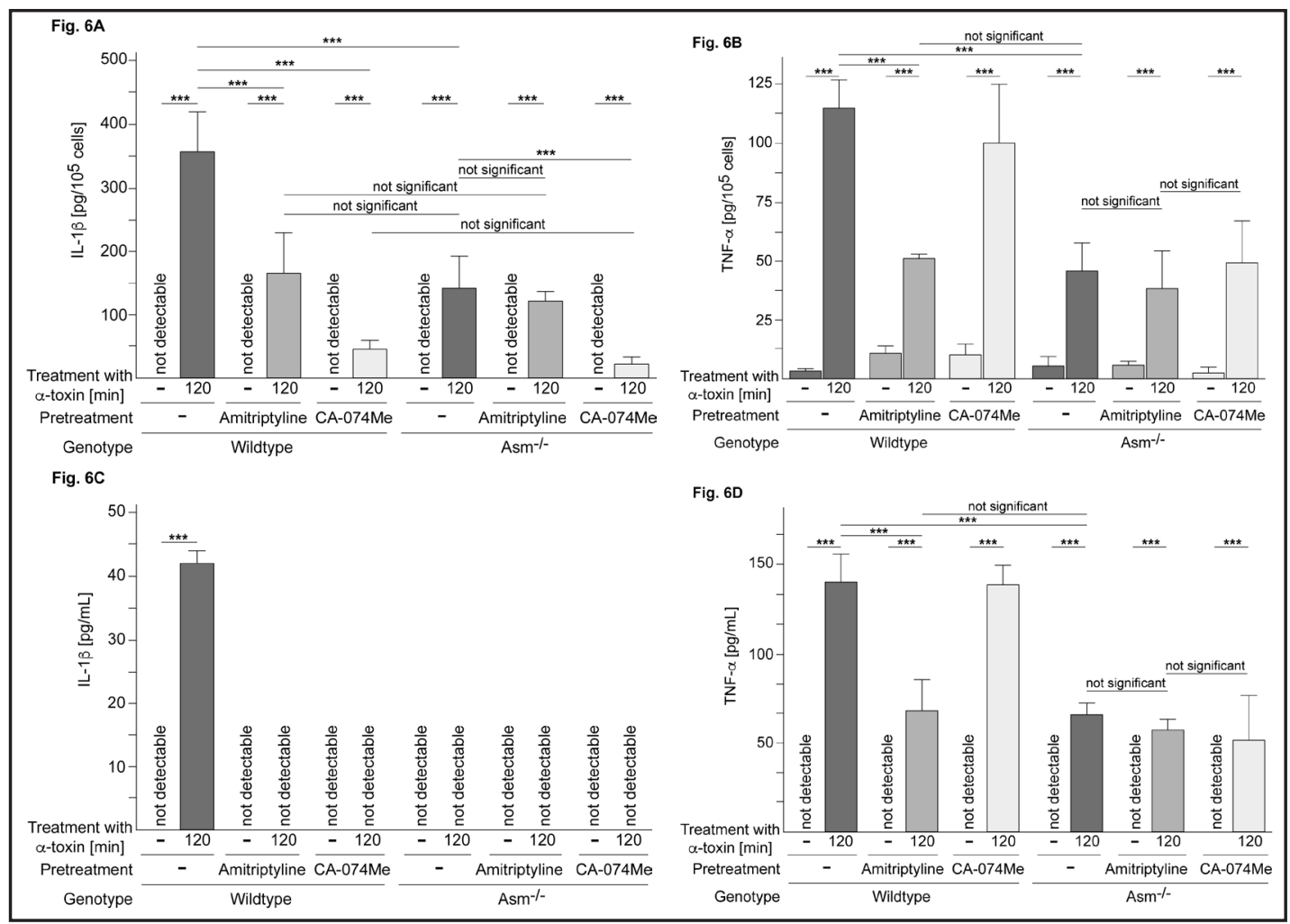

Fig. 6. Genetic deficiency or pharmacological inhibition of the acid sphingomyelinase reduces formation and release of Interleukin $1 \beta$ and TNF- $\alpha$ in macrophages after S. aureus $\alpha$-toxin treatment. Treatment of wildtype macrophages with $S$. aureus $\alpha$-toxin results in formation of Interleukin $1 \beta$ (IL-1 $\beta$ ) (A) and TNF- $\alpha$ (B) as determined by ELISA from the cell pellets, which is reduced by genetic deficiency of the acid sphingomyelinase or pharmacological inhibition of the acid sphingomyelinase using amitriptyline. Pharmacological inhibition of cathepsin B using CA-074Me blocks the formation of IL-1 $\beta$, but is without effect on TNF- $\alpha$ formation. (C) Treatment of macrophages with $\alpha$-toxin results in a release of IL-1 $\beta$ into the supernatant, which is completely abrogated by genetic deficiency of the acid sphingomyelinase, treatment with amitriptyline or the cathepsin B inhibitor CA-074Me. (D) TNF- $\alpha$ is released from wildtype macrophages into the cell culture supernatant after treatment with $\alpha$-toxin, which is reduced by treatment with pharmacological or genetic deficiency of the acid sphingomyelinase, but unaffacted by the cathepsin B inhibitor CA-074Me. Displayed are the mean \pm SD from 3 independent studies, ${ }^{*} \mathrm{p}<0.05$, ANOVA.

further reduced the residual formation and release of IL-1 $\beta$ from acid sphingomyelinasedeficient cells after $\alpha$-toxin treatment (Fig. 6A and C). In contrast, the cathepsin B inhibitor CA-074Me was without effect on the formation and the release of TNF- $\alpha$ after $\alpha$-toxin treatment of macrophages (Fig. 6B and D).

\section{Discussion}

In the present study we identified a novel mechanism how $S$. aureus $\alpha$-toxin induces inflammation. We demonstrate that $\alpha$-toxin causes activation of the acid sphingomyelinase and a formation of ceramides within lysosomes that results in the release of cathepsin $\mathrm{B}$ and D from lysosomes into the cytoplasm. We focused on the initial $2 \mathrm{hrs}$ of the response of macrophages to $\alpha$-toxin, since we assumed that effects of toxins on macrophages result in a rapid response. In fact, our data show a rapid release of cathepsin B into the cytoplasm with a subsequent activation of the inflammasome. However, these data do not exclude that $\alpha$-toxin also induces a long-term activation of the acid sphingomyelinase/ceramide system, which may result in a continuous activation of the inflammasome. Further, a large portion 


\section{Cellular Physiology Cell Physiol Biochem 2017;43:2170-2184 \\ \begin{tabular}{c|c|c|c|} 
DOI: 10.1159/000484296 & (0) 2017 The Author(s). Published by S. Karger AG, Basel \\
www.karger.com/cpb
\end{tabular}}

Ma et al.: Staphylococcus aureus $\alpha$-Toxin Activates the Inflammasome

of the lysosomal cathepsin B has been released from lysosomes and the inflammasome has been activated already 2 hrs after $\alpha$-toxin treatment suggesting that this time period of treatment is sufficient to induce most of the changes investigated in the present manuscript. Cytoplasmic cathepsin B physically associates with Asc and Nlrc4, key components of the inflammasome [36], and thereby activates the inflammasome as determined by a formation and release of IL-1 $\beta$. Moreover, we demonstrate that $\alpha$-toxin triggers the formation of TNF- $\alpha$, at least partly, via acid sphingomyelinase, but independent of cathepsin B. Genetic deficiency or pharmacological inhibition of the acid sphingomyelinase prevented all of these events indicating the key role of the acid sphingomyelinase for the induction of proinflammatory cytokines in macrophages by $S$. aureus $\alpha$-toxin. Lysosomal activation of the acid sphingomyelinase/ceramide system by bacterial toxins might be a novel mechanism how these toxins induce formation of pro-inflammatory cytokines.

At present, it is unknown how $S$. aureus $\alpha$-toxin activates the acid sphingomyelinase. $S$. aureus $\alpha$-toxin binds to its receptor ADAM10 at the plasma membrane [7-10], which is also a pre-requisite for the oligomerization and membrane integration of the toxin [10, 11]. Binding of $\alpha$-toxin to ADAM10 or the wounding upon integration of the toxin into the membrane might trigger translocation of secretory lysosomes that contain the acid sphingomyelinase, to the plasma membrane bringing the acid sphingomyelinase in contact with the toxin. The acid sphingomyelinase may then generate ceramides in the plasma membrane and internalization of ceramide-enriched membrane domains together with the acid sphingomyelinase may finally result in an increase of ceramides within lysosomes. However, it seems to be more likely that the cell internalizes the toxin immediately after membrane incorporation to prevent cell damage and targets the toxin to lysosomes for degradation. Within lysosomes the cell responds to the toxin with an activation of the acid sphingomyelinase, formation of ceramides, the release of cathepsins, an activation of the inflammasome and the release of pro-inflammatory cytokines. The toxin may generate reactive oxygen species within the lysosome that have been previously shown to stimulate the enzyme activity of the acid sphingomyelinase [39, 44-48]. Alternatively, activation of the acid sphingomyelinase by $\alpha$-toxin might be mediated by a direct contact of the acid sphingomyelinase with $\alpha$-toxin and a conformational change of the acid sphingomyelinase [48]. In addition, the toxin may activate proteases that induce a limited cleavage and thereby activation of the acid sphingomyelinase, similar to the activation of the acid sphingomyelinase by caspases in multivesicular bodies [49].

Ceramides have been shown to induce a lysosomal release and activation of cathepsin D $[32,33]$. Cathepsin D has been linked to the induction of endoplasmatic reticulum stress [50], suppression of autophagy [51], degradation of XIAP [52] and induction of apoptosis [53].

It might be possible that ceramide molecules bind to cathepsins and thereby facilitate the translocation of the proteins via the lysosomal membrane [32, 33]. Such a direct interaction of ceramides with cathepsin D has been previously shown [32]. In addition, the acid sphingomyelinase has been shown to be required for the fusion of phagosomes with lysosomes [54] and, thus, targeting of $S$. aureus $\alpha$-toxin to lysosomes might also require the acid sphingomyelinase and the formation of ceramides. The toxin may then permeabilize the lysosomal membrane to allow release of cathepsins. Obviously, these events are not exclusive and the acid sphingomyelinase/ceramide system might have multiple functions in the cellular response to $S$. aureus $\alpha$-toxin.

Ceramides may not be the only lipids that trigger permeabilization of the lysosomal membrane after activation of the acid spingomyelinase. It has been shown that sphingosine generation within lysosomes also mediates lysosomal permeability and compromises lysosomal integrity $[55,56]$. It is certainly possible that $S$. aureus $\alpha$-toxin does not only activate the acid sphingomyelinase, but also the acid ceramidase, and thereby triggers the formation of ceramide and sphingosine. Both lipids might contribute to an increased permeability of lysosomes and the release of cathepsins from the lysosome. An activation of the acid ceramidase with a subsequent formation of sphingosine from lysosomal ceramides, 
would also explain the finding that the release of cathepsins from lysosomes is not completely blocked in acid sphingomyelinase-deficient macrophages, because ceramides can also be generated within lysosomes by hydrolysis from other sphingolipids than sphingomyelin. Since amitriptyline does not only block the acid sphingomyelinase, but also the acid ceramidase [57], this scenario would also explain why this inhibitor further reduces the release of cathepsins in acid sphingomyelinase-deficient cells.

Previous studies by Colombini et al. have shown that ceramide molecules form shortlived pores in mitochondrial membranes [58]. These pores are large enough to permit translocation of polypetides [59]. Similar ceramide channels were recently shown in lysosomes [60] and they may permit the translocation of cathepsin B from the lysosome into the cytoplasm after $S$. aureus $\alpha$-toxin treatment. It will be very interesting to determine different ceramide species in lysosomes after treatment with $S$. aureus $\alpha$-toxin and to measure whether the amounts and species of different ceramides are sufficient to mediate lysosomal ceramide channels.

In addition, ceramide accumulation in organelle membranes might also result in a very brief disruption of the bilayer [61] with a random "translocation" of proteins that attach to this specific area of the lysosomal inner membrane leaflet to the cytoplasm.

It has been previously shown that bacteria activate the inflammasome via cathepsins [62-64]. For instance, it has been previously shown that infection of endothelial cells with Lactobacillus casei results in increased lysosomal permeability and a release of cathepsin B into the cytoplasm, finally mediating stimulation of the Nlrp3 inflammasome and arteritis [64]. Interestingly, free fatty acids such as palmitate also triggered a cathepsin B-mediated activation of the inflammasome [65] and it remains to be determined whether treatment with $S$. aureus $\alpha$-toxin also mediates an intracellular release of free fatty acids contributing to increased lysosomal permeability. However, only a few studies report that bacterial toxins trigger an activation of the inflammasome via cathepsin B $[66,67]$ and none of these studies has linked the acid sphingomyelinase/ceramide pathway to the inflammasome. Thus, it was shown that hemolysin from group B Streptococcus induces lysosomal leakage and inflammasome activation [66]. Likewise, anthrax lethal toxin stimulates the inflammasome, which is prevented by inhibition of cathepsin B [67]. Detailed insights into the mechanisms how these toxins activate the inflammasome require definition.

Our studies show a direct interaction of cathepsin B with Nlrc4 and Asc. Inhibition of cathepsin B4 prevents activation of the inflammasome and the release of IL- $1 \beta$ upon S. aureus $\alpha$-toxin treatment. This suggests that limited cleavage of components of the inflammasome by cathepsin B activates the inflammasome and mediates the release of pro-inflammatory cytokines. In contrast to cathepsin B, we did not detect a $S$. aureus $\alpha$-toxin-triggered association of cathepsin D with components of the inflammasome. Further, inhibition of cathepsin B was sufficient to prevent activation of the inflammasome by $S$. aureus $\alpha$-toxin. Thus, the release of cathepsin $\mathrm{D}$ does not seem to result primarily in activation of the inflammasome and the cellular consequences mediated by the release of cathepsin D from lysosomes into the cytoplasm upon treatment of macrophages with S. aureus $\alpha$-toxin require further studies.

The formation of TNF- $\alpha$ was also dependent on expression of the acid sphingomyelinase and reduced in cells lacking the acid sphingomyelinase or treated with amitriptyline. However, the formation of TNF- $\alpha$ after $\alpha$-toxin-treatment was independent of cathepsin $B$ indicating that the acid sphingomyelinase couples to several independent pathways regulating inflammation.

Our studies further show that genetic deficiency of the acid sphingomyelinase or treatment of WT macrophages with amitriptyline reduces the formation of IL-1 $\beta$ by approximately $50 \%$, while the release of IL-1 $\beta$ from macrophages is completely prevented by genetic or pharmacological blockade of the acid sphingomyelinase. This indicates a dual role of the acid sphingomyelinase, which is important for intracellular formation of IL-1 $\beta$ and absolutely essential for the release of IL-1 $\beta$ from macrophages into the cell culture supernatant. 


\section{Cellular Physiology Cell Physiol Biochem 2017;43:2170-2184

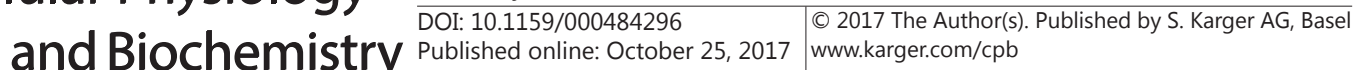

In summary, our studies indicate a novel signaling pathway how $S$. aureus $\alpha$-toxin mediates activation of the inflammasome in macrophages: We demonstrate that the toxin activates the acid sphingomyelinase and triggers a formation of ceramides in lysosomes of bone marrow-derived macrophages. Activation of the acid sphingomyelinase/ceramide pathway results in release of cathepsin B from lysosomes that associates with Nlrc4 and Asc and mediates an activation of the inflammasome finally resulting in formation and release of IL-1 $\beta$. Activation of the acid sphingomyelinase by $\alpha$-toxin also triggers formation and release of TNF- $\alpha$, which is independent of cathepsin B. These data link the lysosomal acid sphingomyelinase/ceramide system to the regulation of cytokines that are central for the regulation of inflammation in many human diseases.

\section{Acknowledgements}

The study was supported by the GRK 2098 to KBF and EG, DFG grant GU 335/33-1 to EG and FOR 2123 (project 6) to MF.

\section{Disclosure Statement}

The authors declare to have no conflicts.

\section{References}

-1 Lowy FD: Staphylococcus aureus infections. N Engl J Med 1998;20:520-532.

2 Klevens RM, Morrison MA, Nadle J, Petit S, Gershman K, Ray S, Harrison LH, Lynfield R, Dumyati G, Townes JM, Craig AS, Zell ER, Fosheim GE, McDougal LK, Carey RB, Fridkin SK: Active Bacterial Core surveillance (ABCs) MRSA Investigators (2007) Invasive methicillin-resistant Staphylococcus aureus infections in the United States. JAMA 2007;298:1763-1771.

-3 Bhakdi S, Suttorp N, Seeger W, Füssle R, Tranum-Jensen J: Molecular basis for the pathogenicity of S. aureus alpha-toxins. Immun Infect 1984;12:279-285.

4 Mattix ME, Hunt RE, Wilhelmsen CL, Johnson AJ, Baze WB: Aerosolized staphylococcal enterotoxin B-induced pulmonary lesions in rhesus monkeys (Macaca mulatta). Toxicol Pathol 1995;23:262-268.

-5 Diep BA, Chan L, Tattevin P, Kajikawa O, Martin TR, Basuino L, Mai TT, Marbach H, Braughton KR, Whitney AR, Gardner DJ, Fan X, Tseng CW, Liu GY, Badiou C, Etienne J, Lina G, Matthay MA, DeLeo FR, Chambers HF: Polymorphonuclear leukocytes mediate Staphylococcus aureus Panton-Valentine leukocidin-induced lung inflammation and injury. Proc Natl Acad Sci USA 2010;107:5587-5592.

6 Ménoret A, Kumar S, Vella AT: Cytochrome b5 and cytokeratin 17 are biomarkers in bronchoalveolar fluid signifying onset of acute lung injury. PLoS One 2012;7:e40184.

7 Bubeck Wardenburg J, Patel RJ, Schneewind O: Surface proteins and exotoxins are required for the pathogenesis of Staphylococcus aureus pneumonia. Infect Immun 2007;75:1040-1044.

-8 Inoshima I, Inoshima N, Wilke GA, Powers ME, Frank KM, Wang Y, Bubeck Wardenburg J: A Staphylococcus aureus pore-forming toxin subverts the activity of ADAM10 to cause lethal infection in mice. Nat Med 2011;17:1310-1314.

-9 Inoshima N, Wang Y, Bubeck Wardenburg J: Genetic requirement for ADAM10 in severe Staphylococcus aureus skin infection. J Invest Dermatol 2012;132:1513-1516.

10 Wilke GA, Bubeck Wardenburg J. Role of a disintegrin and metalloprotease 10 in Staphylococcus aureus $\alpha$-hemolysin mediated cellular injury. Proc Natl Acad Sci USA 2010;107:13473-13478.

11 Powers ME, Kim HK, Wang Y, Bubeck Wardenburg J: ADAM10 mediates vascular injury induced by Staphylococcus aureus $\alpha$-hemolysin. J Infect Dis 2012;206:352-356.

12 Ezekwe Jr. EAD, Wenig C, Duncan JA: ADAM10 cell surface expression but not activity is critical for Staphylococcus aureus $\alpha$-hemolysin-mediated activation of the NLRP3 inflammasome in human monocytes. Toxin 2016;8:95,1-14. 


\section{Cellular Physiology Cell Physiol Biochem 2017;43:2170-2184 \begin{tabular}{l|l} 
and Biochemistry & DOI: 10.1159/000484296 \\
Published online: October 25, 2017 & $\begin{array}{l}\text { (C) 2017 The Author(s). Published by S. Karger AG, Basel } \\
\text { www.karger.com/cpb }\end{array}$
\end{tabular}}

Ma et al.: Staphylococcus aureus $\alpha$-Toxin Activates the Inflammasome

13 Grassmé H, Gulbins E, Brenner B, Ferlinz K, Sandhoff K, Harzer K, Lang F, Meyer TF: Acidic sphingomyelinase mediates entry of $N$. gonorrhoeae into nonphagocytic cells. Cell 1997;91:605-615.

- 14 Hauck CR, Grassmé H, Bock J, Jendrossek V, Ferlinz K, Meyer TF, Gulbins E: Acid sphingomyelinase is involved in CEACAM receptor-mediated phagocytosis of Neisseria gonorrhoeae. FEBS Letters 2000;478:260-266.

15 Grassmé H, Jendrossek V, Riehle A, von Kurthy G, Berger J, Schwarz H, Weller M, Kolesnick R, Gulbins E: Host defense against Pseudomonas aeruginosa requires ceramide-rich membrane rafts. Nat Med 2003;9:322-330.

16 Grassmé H, Henry B, Ziobro R, Becker KA, Riethmüller J, Gardner A, Seitz AP, Steinmann J, Lang S, Ward C, Schuchman EH, Caldwell CC, Kamler M, Edwards MJ, Brodlie M, Gulbins E: $\beta 1$-Integrin accumulates in cystic fibrosis luminal airway epithelial membranes and decreases sphingosine, promoting bacterial infections. Cell Host Microbe 2017;21:707-718.

17 Teichgräber V, Ulrich M, Endlich N, Riethmüller J, Wilker B, De Oliveira-Munding CC, van Heeckeren AM, Barr ML, von Kürthy G, Schmid KW, Weller M, Tümmler B, Lang F, Grassme H, Döring G, Gulbins E: Ceramide accumulation mediates inflammation, cell death and infection susceptibility in cystic fibrosis. Nat Med 2008;14:382-391.

18 Peng H, Li C, Kadow S, Henry BD, Steinmann J, Becker KA, Riehle A, Beckmann N, Wilker B, Li PL, Pritts T, Edwards MJ, Zhang Y, Gulbins E, Grassmé H: Acid sphingomyelinase inhibition protects mice from lung edema and lethal Staphylococcus aureus sepsis. J Mol Med (Berl) 2015;93:675-689.

19 Li C, Wu Y, Orian-Rousseau V, Zhang Y, Gulbins E, Grassme H: Regulation of Staphylococcus aureus infection of macrophages by CD44, reactive oxygen species and acid sphingomyelinase. Antioxid Redox Signal doi: 10.1089/ars.2017.6994.

20 Li C, Wu Y, Riehle A, Ma J, Kamler M, Gulbins E, Grassmé H: Staphylococcus survives in cystic fibrosis macrophages forming a reservoir for chronic pneumonia. Infect Immun 2017 Mar 13. pii: IAI.00883-16. doi: 10.1128/IAI.00883-16.

-21 Esen M, Schreiner B, Jendrossek V, Lang F, Fassbender K, Grassmé H, Gulbins E: Mechanisms of Staphylococcus aureus induced apoptosis of human endothelial cells. Apoptosis 2001;6:431-439.

22 Grassmé H, Riehle A, Wilker B, Gulbins E: Rhinoviruses infect human epithelial cells via ceramide-enriched membrane platforms. J Biol Chem 2005;280:26256-26262.

23 Fowler S: Lysosomal localization of sphingomyelinase in rat liver. Biochim Biophys Acta 1969;191:481-484.

-24 Perrotta C, Bizzozero L, Cazzato D, Morlacchi S, Assi E, Simbari F, Zhang Y, Gulbins E, Bassi MT, Rosa P, Clementi E: Syntaxin 4 is required for acid sphingomyelinase activity and apoptotic function. J Biol Chem 2010;285:40240-40251.

25 Grassmé H, Jekle A, Riehle A, Schwarz H, Berger J, Sandhoff K, Kolesnick R, Gulbins E: CD95 signaling via ceramide-rich membrane rafts. J Biol Chem 2001;276:20589-20596.

-26 Nurminen TA, Holopainen JM, Zhao H, Kinnunen PK: Observation of topical catalysis by sphingomyelinase coupled to microspheres. J Am Chem Soc 2002;124:12129-12134.

-27 Nicolay JP, Gatz S, Liebig G, Gulbins E, Lang F: Amyloid induced suicidal erythrocyte death. Cell Physiol Biochem 2007;19:175-184.

28 Lee H, Rotolo JA, Mesicek J, Penate-Medina T, Rimner A, Liao W-C, Yin X, Ragupathi G, Ehleiter D, Gulbins E, Zhai D, Reed JC, Haimovitz-Friedman A, Fuks Z, Kolesnick R: Mitochondrial ceramide-rich macrodomains functionalize Bax upon irradiation. PLoS One 2011;6:e19783.

29 Bock J, Szabo I, Gamper N, Adams C, Gulbins E: Ceramide inhibits the potassium channel Kv1.3 by the formation of membrane platforms. Biochem Biophys Res Commun 2003;305:890-897.

-30 Lang F, Madlung J, Uhlemann AC, Risler T, Gulbins E: Cellular taurine release triggered by stimulation of the Fas(CD95) receptor in Jurkat lymphocytes. Pflügers Arch 1998;436:377-383.

- 31 Grassmé H, Bock J, Kun J, Gulbins E: Clustering of CD40 ligand is required to form a functional contact with CD40. J Biol Chem 2002;277:30289-30299.

-32 Heinrich M, Wickel M, Schneider-Brachert W, Sandberg C, Gahr J, Schwandner R, Weber T, Saftig P, Peters C, Brunner J, Krönke M, Schütze S: Cathepsin D targeted by acid sphingomyelinase-derived ceramide. Embo J 1999;18:5252-5263.

-33 Heinrich M, Neumeyer J, Jakob M, Hallas C, Tchikov V, Winoto-Morbach S, Wickel M, Schneider-Brachert W, Trauzold A, Hethke A, Schütze S: Cathepsin D links TNF-induced acid sphingomyelinase to Bid-mediated caspase- 9 and -3 activation. Cell Death Differ 2004;11:550-563. 


\section{Cellular Physiology Cell Physiol Biochem 2017;43:2170-2184 and Biochemistry DOI: 10.1159/000484296 25,2017 Published 2017 The Author(s). Published by S. Karger AG, Basel

-34 Zhang AY, Yi F, Jin S, Xia M, Chen QZ, Gulbins E, Li PL: Acid sphingomyelinase and its redox amplification in formation of lipid raft redox signaling platforms in endothelial cells. Antioxid Redox Signal 2007;9:817828.

-35 Boini KM, Xia M, Koka S, Gehr TW, Li PL: Instigation of NLRP3 inflammasome activation and glomerular injury in mice on the high fat diet: role of acid sphingomyelinase gene. Oncotarget 2016;7:19031-19044.

-36 Abais JM, Xia M, Zhang Y, Boini KM, Li P: Redox regulation of NLRP3 inflammasomes: ROS as trigger or effector? Antioxid Redox Signal 2015;22:1111-1129.

-37 Horinouchi K, Erlich S, Perl DP, Ferlinz K, Bisgaier CL, Sandhoff K, Desnick RJ, Stewart CL, Schuchman EH: Acid sphingomyelinase deficient mice: a model of types A and B Niemann-Pick disease. Nat Genet 1995;10:288-293.

- 38 Lozano J, Morales A, Cremesti A, Fuks Z, Tilly JL, Schuchman E, Gulbins E, Kolesnick R: Niemann-Pick disease versus acid sphingomyelinase deficiency. Cell Death Differ 2001;8:100-103.

-39 Zhang Y, Li X, Carpinteiro A, Gulbins E: Acid sphingomyelinase amplifies redox signaling in Pseudomonas aeruginosa-induced macrophage apoptosis. J Immunol 2008;181:4247-4254.

40 Hurwitz R, Ferlinz K, Sandhoff K: The tricyclic anti-depressant desipramine causes proteolytic degradation of lysosomal sphingo-myelinase in human fibroblasts. Biol Chem Hoppe Seyler 1994;375:447-450.

-41 Becker KA, Riethmüller J, Lüth A, Döring G, Kleuser B, Gulbins E: Acid sphingomyelinase inhibitors normalize pulmonary ceramide and inflammation in cystic fibrosis. Am J Respir Cell Mol Biol 2009;42:716724.

42 Kornhuber J, Tripal P, Reichel M, Terfloth L, Bleich S, Wiltfang J, Gulbins E: Identification of new functional inhibitors of acid sphingomyelinase using a structure-property-activity relation model. J Med Chem 2008;51:219-237.

43 Gulbins E, Palmada M, Reichel M, Lüth A, Böhmer C, Amato D, Müller CP, Tischbirek CH, Groemer TW, Tabatabai G, Becker KA, Tripal P, Staedtler S, Ackermann TF, v. Brederode J, Alzheimer C, Weller M, Lang UE, Kleuser B, Grassmé H, Kornhuber J: Acid sphingomyelinase/ceramide system mediates effects of antidepressant drugs. Nat Med 2013;19:934-938.

44 Dumitru CA, Gulbins E: TRAIL activates acid sphingomyelinase via a redox mechanism and releases ceramide to trigger apoptosis. Oncogene 2006;25:5612-5625.

45 Li X, Gulbins E, Zhang Y: Oxidative stress triggers $\mathrm{Ca}^{2+}$-dependent lysosome trafficking and activation of acid sphingomyelinase. Cell Physiol Biochem 2012;30:815-826.

46 Henry B, Ziobro R, Becker KA, Kolesnick R, Gulbins E: Acid sphingomyelinase. Handb Exp Pharmacol 2013;215:77-88.

47 Qiu H, Edmunds T, Baker-Malcolm J, Karey KP, Estes S, Schwarz C, Hughes H, Van Patten SM: Activation of human acid sphingomyelinase through modification or deletion of C-terminal cysteine. J Biol Chem 2003;278:32744-32752.

48 Gulbins E, Welsch J, Lepple-Wienhuis A, Heinle H, Lang F: Inhibition of Fas-induced apoptotic cell death by osmotic cell shrinkage. Biochem Biophys Res Commun 1997;236:517-521.

-49 Edelmann B, Bertsch U, Tchikov V, Winoto-Morbach S, Perrotta C, Jakob M, Adam-Klages S, Kabelitz D, Schütze S: Caspase-8 and caspase-7 sequentially mediate proteolytic activation of acid sphingomyelinase in TNF-R1 receptosomes. EMBO J 2011;30:379-394.

-50 Uchiyama Y: Autophagic cell death and its execution by lysosomal cathepsins. Arch Histol Cytol. 2001;64:233-246.

51 Liu F, Li X, Lu C, Bai A, Bielawski J, Bielawska A, Marshall B, Schoenlein PV, Lebedyeva IO, Liu K: Ceramide activates lysosomal cathepsin B and cathepsin D to attenuate autophagy and induces ER stress to suppress myeloid-derived suppressor cells. Oncotarget 2016;7:83907-83925.

52 Taniguchi M, Ogiso H, Takeuchi T, Kitatani K, Umehara H, Okazaki T: Lysosomal ceramide generated by acid sphingomyelinase triggers cytosolic cathepsin B-mediated degradation of X-linked inhibitor of apoptosis protein in natural killer/T lymphoma cell apoptosis. Cell Death Dis 2015;6:e1717.

53 Deiss LP, Galinka H, Berissi H, Cohen O, Kimchi A: Cathepsin D protease mediates programmed cell death induced by interferon-gamma, Fas/APO-1 and TNF-alpha. EMBO J 1996;15:3861-3870.

-54 Utermöhlen 0, Herz J, Schramm M, Krönke M: Fusogenicity of membranes: the impact of acid sphingomyelinase on innate immune responses. Immunobiology 2008;213:307-314. 


\section{Cellular Physiology Cell Physiol Biochem 2017;43:2170-2184 \begin{tabular}{ll|l} 
DOI: 10.1159/000484296 25,2017 & $\begin{array}{l}\text { O 2017 The Author(s). Published by S. Karger AG, Basel } \\
\text { www.karger.com/cpb }\end{array}$
\end{tabular}}

-55 Ullio C, Casas J, Brunk UT, Sala G, Fabriàs G, Ghidoni R, Bonelli G, Baccino FM, Autelli R: Sphingosine mediates TNF $\alpha$-induced lysosomal membrane permeabilization and ensuing programmed cell death in hepatoma cells. J Lipid Res 2012;53:1134-1143.

-56 Höglinger D, Haberkant P, Aguilera-Romero A, Riezman H, Porter FD, Platt FM, Galione A, Schultz C. Intracellular sphingosine releases calcium from lysosomes. Elife 2015;4: pii: e10616.

57 Elojeimy S, Holman DH, Liu X, El-Zawahry A, Villani M, Cheng JC, Mahdy A, Zeidan Y, Bielwaska A, Hannun YA, Norris JS: New insights on the use of desipramine as an inhibitor for acid ceramidase. FEBS Letters 2006;580:4751-4756.

-58 Siskind LJ, Colombini M: The lipids C2- and C16-ceramide form large stable channels. The Journal of Biological Chemistry 2000;275:38640-38644.

59 Colombini M: Ceramide channels and their role in mitochondria-mediated apoptosis. Biochimica et Biophysica Acta 2010;1797:1239-1244.

60 Yamanea M, Moriyaa S, Kokuba H: Visualization of ceramide channels in lysosomes following endogenous palmitoyl-ceramide accumulation as an initial step in the induction of necrosis. Biochemistry and Biophysics Reports 2017;11:174-181.

61 Artetxe I, Ugarte-Uribe B, Gil D, Valle M, Alonso A, García-Sáez AJ, Goñi FM: Does ceramide form channels? The ceramide-induced membrane permeabilization mechanism. Biophys J 2017;113:860-868.

62 Lee HM, Kang J, Lee SJ, Jo EK: Microglial activation of the NLRP3 inflammasome by the priming signals derived from macrophages infected with mycobacteria. Glia 2013;61:441-52

-63 Duncan JA, Gao X, Huang MT, O'Connor BP, Thomas CE, Willingham SB, Bergstralh DT, Jarvis GA, Sparling PF, Ting JP: Neisseria gonorrhoeae activates the proteinase cathepsin B to mediate the signaling activities of the NLRP3 and ASC-containing inflammasome. J Immunol 2009;182:6460-6469.

64 Chen Y, Li X, Boini KM, Pitzer AL, Gulbins E, Zhang Y, Li PL: Endothelial Nlrp3 inflammasome activation associated with lysosomal destabilization during coronary arteritis. Biochim Biophys Acta 2015;1853:396408.

65 Wang L, Chen Y, Li X, Zhang Y, Gulbins E, Zhang Y: Enhancement of endothelial permeability by free fatty acid through lysosomal cathepsin B-mediated Nlrp3 inflammasome activation. Oncotarget 2016; 7:7322973241.

66 Gupta R, Ghosh S, Monks B, DeOliveira RB, Tzeng TC, Kalantari P, Nandy A, Bhattacharjee B, Chan J, Ferreira F, Rathinam V, Sharma S, Lien E, Silverman N, Fitzgerald K, Firon A, Trieu-Cuot P, Henneke P, Golenbock DT: RNA and $\beta$-hemolysin of group B Streptococcus induce interleukin-1 $\beta$ (IL-1 $\beta$ ) by activating NLRP3 inflammasomes in mouse macrophages. J Biol Chem 2014;289:13701-13705.

67 Ali SR, Timmer AM, Bilgrami S, Park EJ, Eckmann L, Nizet V, Karin M: Anthrax toxin induces macrophage death by $\mathrm{p} 38$ MAPK inhibition but leads to inflammasome activation via ATP leakage. Immunity 2011;35:34-44. 